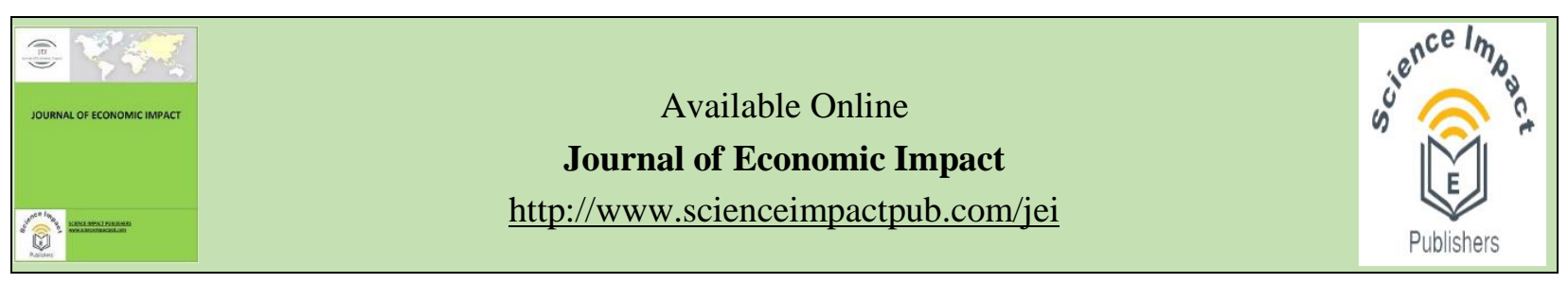

\title{
MANAGING CLIMATE CHANGE FOR WHEAT PRODUCTION: AN EVIDENCE FROM SOUTHERN PUNJAB, PAKISTAN
}

\author{
Muhammad Haseeb Raza ${ }^{\mathrm{a}, *}$, Allah Bakhsh ${ }^{\mathrm{b}}$, Muhammad Kamran ${ }^{\mathrm{c}}$ \\ ${ }^{a}$ College of Economics \& Management, Huazhong Agricultural University, Wuhan 430070, P.R.China \\ ${ }^{\mathrm{b}}$ Institute of Agricultural Extension and Rural Development, University of Agriculture, Faisalabad, Pakistan \\ ${ }^{c}$ Department of Agronomy, University College of Agriculture, University of Sargodha-40100, Pakistan
}

\section{HIGHLIGHTS}

- The impact of temperature and precipitation are both positive and negative on crop productivity.

- High temperature at initial stage of wheat crop in December negatively affect the crop productivity, while high temperature has positive impact at later stages of wheat crop.

- Gradually high precipitation on sowing stage positively affect seed germination.

- Precipitation at vegetative growth stage positively affect wheat growth.

- Increase in Precipitation at harvesting level increases the harvesting losses.

ABSTRACT
The current research study was conducted to estimate the impact of climate change on wheat production by using panel
data from 1998-2014. For this purpose four districts were selected from southern Punjab, Pakistan. Panel model of
fixed effect (FE) was estimated at region level for wheat productivity utilizing climatic and non-climatic variables based
on season. The conclusion of the study showed that non-climatic, i.e. inputs, number of tractors, area under wheat,
number of tube wells and fertilizer consumption in each district have significant impact on the wheat production. The
fixed effect model results revealed that the increase in temperature has significance impact on the month of the
November and January, while it showed negative impact in the month of April. The results also showed a non-linear
relationship of precipitation for the months of April and November.

Keywords: Climate change; Punjab; Pakistan; wheat production; panel data.

Received: April 18, 2019; Accepted: May 21, 2019; Published: June 2, 2019.

* Correspondence: College of Economics \& Management, Huazhong Agricultural University, Wuhan 430070, P.R.China

Email: haseebrizvi00@yahoo.com

\section{Introduction}

Pakistani climate is comparatively more susceptible to change due to the warmer climatic conditions. The reason is the region where Pakistan is situated, the expected average temperature increase is higher than the global. Nearly 60 percent area receive about $250 \mathrm{~mm}$ rain annually and $24 \%$ area has $250-500 \mathrm{~mm}$, so it is constituted with mostly arid and semi-arid land. Economy of Pakistan is based on agriculture, so impact of climate change is highly sensitive the growth of the economy. Changing monsoon rains caused the floods and extended droughts. Combining all these factors caused serious threat to the water, food and energy security in Pakistan (TFCC, 2010). Population wise, Punjab is at first number while area wise it is second biggest province of Pakistan. Contributing $56 \%$ share in Pakistan's gross domestic product and having about 57 $\%$ land in agriculture sector dominates the Punjab landscape (GOP, 2014).

The study under hand is conducted to find new methods and techniques to reduce the economic impact of changing climate. The Authorities responsible for policy making should consider the results and recommendation of the study while developing climate policies.

The major staple food of Pakistani people is wheat. Being the first staple food of Pakistan, wheat covers an important place in government policies regarding agriculture. It lends $2.2 \%$ in GDP and $10.3 \%$ to the value added in agriculture. The yield per hectare being 2787 (Kgs/hec) in 2012-13 resulted in the positive growth of $2.7 \%$ Instead of $4.2 \%$ negative growth that happened last year (GOP, 2015). In Pakistan, $120 \mathrm{~kg}$ per head consumption of wheat, makes it more important food crop. In Pakistan the available water for wheat cultivation is 26 million acre feet (MAF) and that is 28.6 percent lesser than the normal water requirement (Rosegrant et al., 2008). In Pakistan, wheat occupies 9.06 million hectares, means the largest area under any single crop. During the period of 1948-2004, production of 
wheat increased 480 percent and there was 114 percent increase in area (Kisana, 2004).

The main reasons for lesser acreage under wheat crop are, shortage of water (accessibility on farm gate) and lesser rainfall in the sowing period. In Wheat cultivation, an increase of $0.5 \%$ is seen this year, being 8693 thousand hectares this year and 8650 thousand hectares last year. The lower acreage and water shortages is showing its effects in the form of low wheat produce, which is regarded to be lesser than 25 million tons which was the target of 2012-2013. Under changing climatic conditions, the measurements of agronomic and economic index that are making productiveness of agricultural zones worse is of extreme importance. It is preferable to calculate main variables beforehand for the sensible environment of planning, for taking correct choice regarding an important section, for security of food and for long run planning. Wheat crop is exposed to the dangers of various epidemics such as pests, diseases, lodging by winds and grain shriveling due to sudden rise in temperature at grain maturity stage.

Rise in temperature and water scarcity are severe threats to climate stability. Crop and geographic information systems and their combination in the form of maps are helpful to mitigate such severe climatic conditions and predict spatial impacts of changes in agro climate that determine the irrigation requirements (Shabbir et al., 2011). An experienced farmer can easily anticipate the extent of loss in output caused by these problems. It was found that during the year 2002-03, decline was 9.9 Munds per acre as compared to last year. According to farmers' perceptions attack of aphids/jassids more rainfall at maturity stage and cold wind blow was the main causes of yield decline in the area. Low temperature, water shortage and disease attack were the other causes of yield decline during Rabi 200203. According to farmers, the pesticides companies were suggesting pesticides for aphids/jassids control, whereas, the extension department was against the spray at this stage. There was a mix response regarding the control of aphids/jassids by pesticides. It was, therefore suggested that there should be an integrated approach of both extension and field staff of private companies to avoid confusion among the farmers for control of such attack in future (Bashir et al., 2006).

The status of food security and nutrition, especially in developing countries, will worsen if the observed trend in wheat supply and demand continues and future sources of productivity growth are not found (Rejesus et al., 1999). The need of the hour is to calculate the effect of changing climate on different sectors of economy for policy making and planning. Although, it's slightly simple to evaluate the economic influence of climatic change on various economic fields, but it is of critical significance for the Authorities who makes national plans and policies to take into consideration the obstacles of limited available resources and to make the developmental plans for the country in most suitable manner (TFCC, 2010). Wheat is taken as targeted commodity in Pakistan mainly because it is a vital product in the diet of those who are below the poverty line, and in addition it characterizes a significant commodity in terms of its input to national food security. Many researches have been related to climate change and latest researches have predicted that due to climate change the pattern of rain fall and variation in temperature can occur, and the temperature increase at the end of the century in South Asia is predicted to be 3$4{ }^{\circ} \mathrm{C}$ (DEFRA, 2005). Assessing climate impacts on agriculture have increasingly become major areas of scientific concerns, e.g. valuation of climate impacts on wheat production (Rajin et al., 2007; Wei et al., 2005; Yang et al., 2011). The wheat production remained different among districts; it is required to evaluate the factors which cause the variation in productivity.

The wheat production remained different among districts; it is required to evaluate the factors which cause the variation in productivity. Therefore, this study has been designed to analyze the impact of climate change on wheat production and to suggest recommendations for wheat growers and policy makers on the basis of estimated research results of this study. Climate change has severe impact on food security of a country by reducing crop productivity and increasing production losses. For making right decisions regarding the production strategies of wheat with respect to severe climatic threats, it is necessary to critically analyze the key factors required for a reasonable planning to ensure the ultimate food security of Pakistan. The current study in hand is therefore is going to be an essential part of the impact of climate changes on agriculture production. By using the results and recommendations policy makers can develop policies for reducing the severe threats of climate changes on agricultural crops based upon ground realities.

\section{Material and Methods}

The current research study was conducted in Institute of Agricultural and Resource Economics, University of Agriculture Faisalabad, Pakistan in 201415. Punjab is the mixture of different agro-ecological zones, some areas are rice-wheat zone, some are mixed cropping zone, some are cotton-wheat zone, some are low intensity cropping zone and some areas are barani zone. Cotton-wheat agro-ecological zone was selected to represent all wheat growing areas of Southern Punjab for the purpose of current analysis. In the total wheat production of the country cotton-wheat zone contributes 40.4 percent. From cotton-wheat zone Multan, Rahim Yar khan, Bahalnagar and Bahawalpur districts were selected respectively. These four districts were selected based on their Meteorological Station, as discussed above.

\section{Data and Description of Variables}

For irrigation in Punjab, canals are made to provide water from the main rivers, which are the Indus River, and its branches, Jhelum River and Chanab River. In some areas requirement of water is fulfilled with Tube wells. The four district's data, which are representing the 
hot climate as well, was taken to carry out the study. Climate observation stations present in these four districts namely Multan, Bahawalpur, Bahawalnagar and Rahim Yar Khan, are the main reason of selection.

\section{Theoretical framework of the study}

Over time the same cross-sectional unit is surveyed in panel data. So, there is time and space dimensions in panel data. There may exist some group effect, time effect or both in panel data and F.E model (Fixed-Effect) and R.E model (Random-Effect) are utilized to analyze them. A panel is a cross-section (either firm or individual or group of people) and for a specific time period, it is surveyed. The panel data sets (the data sets on various cross sections for a specific time period) assist the Research workers in representing the variation of characteristics in a cross section. The main part of panel data analysis is Heterogeneity across cross sections (Units) (Greene, 2003). The effects regarding specific area can assimilate unnoticed time in different square matrix of the dependent variable that is why the district fixed effect was included. If we apply the district fixed effect, model shows constant slopes whose point differ in time accordance. There are unnoticed characters, like the root of deviation (i.e. the liking for agricultural land in particular district, agricultural activities etc.).These unnoticed characters are over time but differ from one place to place (Stock and Watson, 2003). Two basic approaches, The Random Effect (RE) and The Fixed Effect (FE) are used to calculate the country-specific effects as proposed by the literature. Fixed effect model was selected for the time variant variables while random effects model was selected for time invariant variable using F-test, Housman specification test and BreuschPagan Lagrange multiplies test (Javed et al., 2016). Fixed effect model has many advantages like it controls the adjustments that farmers have made to synchronize with the climate and the variations between one province to the other and it also controls the permanent variations between different places that include the climate as well as other variations that are hard to evaluate. In short the fixed effect approach is a perfect method to evaluate short term reactions to sudden change in weather conditions (Mendelsohn and Dinar, 2009). Hausman test is performed to insure that the hypothesis is correct and proper model specification is utilized. The Fixed Effect Model (FEM) is considered to be most befitting approach, because applying the null hypothesis "no relationship among the place specific effects and the regressors" it will probably be rejected (Greene, 2003). Furthermore, in fixed effect regression models modified Wald test is carried out for group wise heteroscedasticity and for panel data autocorrelation, the Wooldridge test has been carried out. These measures are taken to observe any misspecification problems. Constant variance which is also called homoskedasticity, is null hypothesis in Wald test. But the null hypothesis is rejected, so heteroskedasticity is confirmed. And in Wooldridge test the null hypothesis of no serial correlation could not be rejected so the data does not have first-order correlation is confirmed. If the model is already in the logarithm form then there is no need to apply Wooldridge test and it is directly used in log form. Therefore, strong standard errors are calculated to make sure that the statistical inference are trustworthy. A post estimation test is performed to see whether time fixed effects are needed, to control the time effects whenever the unpredicted variation or special events may affect the outcome variable. It is a joint test to check if the dummies for all years are equal to zero then there is no need for time fixed effects. But the time fixed effects are needed because the null hypothesis that says that all year's coefficients are equal to zero is rejected.

\section{Fixed Effect Model}

Assuming that the slope is same and the variance across the subjects is constant, group difference in the intercepts are examined in group effect model. The assumption that is made in this formulation of model is that the differences across the units can be represented in differences in the constant term. Because a person specific group effect is time constant and thought to be intercept part so the ui is permitted to be linked to different regressors.

$$
Y_{i t}=\beta_{0}+\beta_{1} X_{i t}++\beta_{3} Z_{i t}+e_{i t}
$$

In Eq. 1 the method of Least Square by fixed effect Region-level panel analysis, Fixed effect models use vector of all climatic and non-climatic variables for wheat productivity in the district " $i$ " where time period is " $t$ ". In fact the OLS (Ordinary least Square) regressions with artificial copies of the districts are the fixed effect model.

\section{The Panel Model Basics}

The econometric structure is given here that is utilized to calculate the economic influence of climatic variation on wheat productivity of Southern Punjab. The description of the model included the regression of wheat production over climatic and non-climatic variables for 1983-2013, whereas dealing with the other non-climatic variables that are impacting the agricultural land. The data for the selected four districts of Southern Punjab is collected for 30 years. To calculate the wheat productivity role in Southern Punjab, regression on climatic and non-climatic (control) variables of wheat productivity on district level was done. To estimate the contribution of climatic factors which affect the agriculture productivity various econometric tools and techniques were used. These tools and techniques used the information on crop productivity and production, area sown, irrigation employed, fertilizer use, precipitation, temperature, dummy variable for different locations and machinery used. The present study has heavily relay on the previous research work (Lee et al., 2012; Mendelsohn et al., 1994). The general form of regression model that has been used in the present study was be as follow:

$\mathrm{Y}=\mathrm{Y}(\mathrm{TW}, \mathrm{Trt}, \mathrm{F}, \mathrm{A}, \mathrm{C})$ 
Here,

$\mathrm{Y}=$ Wheat production (Thousand tonnes)

$\mathrm{TW}=$ Total number of diesel and electric tube wells (private and ownership) installed

$\operatorname{Tr} \mathrm{r}=$ Total number of tractors by ownership and private purchase

$\mathrm{F}=$ Total consumption of fertilizer (NPK) in nutrients ton

$\mathrm{A}=$ Area sown under wheat (Thousand Hectares)

$\mathrm{C}=$ Climate variables (Monthly mean temperature and precipitation).

The basic type of regressions calculated by panel data includes within-unit-time, between- unit and between time regressions. These parts shows the various results of the subjacent economic processes.

It shows the specific form of function to measure the productivity which seems as Cobb Douglas type production function (Mundlak, 1988), here the elasticities are the function of the state variables and probably of input. In panel data when climatic variables are related with agricultural characteristics then special type of agriculture production function is used to measure the impacts of climatic impact related with agriculture characteristics (Mundlak et al., 1999). Three largely utilized models for climatic effect study are The Experimental model (Agronomic-Economic model), The Cross Section Model (The Ricardian model) and The Simulation Model. Nonetheless, a productivity model is utilized for analysis, because of the features of the region level panel analysis. This specification form of the agricultural productivity model in the analysis was also recently used (Lee et al., 2012; Mendelsohn et al., 1994), is as follows;

The Standard Model is:

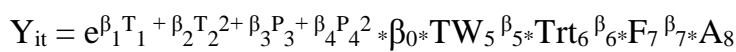
$\beta_{8 * e^{\text {uit }}}$

By taking Logarithm on left and right hand side, The F.E panel model becomes as:

$\ln Y_{\text {it }}=\beta_{0}+\beta_{1} C_{1}+\beta_{2} C_{2}{ }^{2}+\beta_{3} \ln \operatorname{lW}_{3}+\beta_{4} \ln \operatorname{Trt}_{4}+\beta_{5} \operatorname{lnF}_{5}+$ $\beta_{6} \ln \mathrm{A}_{6}+\mu_{\mathrm{it}}$

Here, $\mathrm{C} 1=$ Climatic Variables vector,

$\mathrm{C} 2=$ Squared Climatic Variables Vector,

$\mathrm{L}=$ Labor, I= Irrigation, $\mathrm{M}=$ Machinery, and F= Fertilizer.

$\mu=$ Error term.

Review of literature suggested that, relationship between agriculture productivity/production and climatic variables and non-climatic variables is mostly nonlinear. In order to calculate the anticipated marginal effects of climatic and non-climatic variables on wheat productivity, from non-linear model formula

(Kurukulasuriya and Mendelsohn, 2008) would be employed in the study. Assuming second degree polynomial being used in the regression analysis, this formula can be written as:

$\mathrm{E}\left[\frac{\mathrm{dy}}{\mathrm{dx}}\right]=\left[\beta_{1, \mathrm{i}}+2 \times \beta_{2, \mathrm{i}} \times \mathrm{E}\left(\mathrm{X}_{\mathrm{i}}\right)\right] * \mathrm{E}\left(\mathrm{Y}_{\mathrm{i}}\right)$

In this equation symbol " $\beta_{2, i}$ " is linear coefficient and symbol is square term coefficients for temperature and precipitation variables is denoted by " $\beta_{2, i}$ ". Temperature and precipitation variables mean value is denoted by "E(Xi)" and "E(Yi)" is mean value of the dependent variable. Climatic variable's elasticity formula is given below and the symbols in the equation are identical to the marginal effects formula above;

$\mathrm{E}\left[\frac{d y}{d x \mathrm{i}}\right]=\left[\beta_{1, \mathrm{i}}+2 \times \beta_{2, \mathrm{i}} \times \mathrm{E}\left(\mathrm{X}_{\mathrm{i}}\right)\right] * \mathrm{E}\left(\mathrm{X}_{\mathrm{i}}\right)$

To check the impact of various explanatory variables on the dependent variable, an econometric model is valuable tool for research worker. What's important is that potential multicollinearity is present inherently in climate variables and their square terms. The fixed effects would be deducted by regression software in two steps (Stock and Watson, 2003). First step is subtraction of object specific average from each variable. And the Second step, calculation of regression utilizing entity demeaned variables. For calculation of regression E. Views software package is utilized, and to avoid multicollinearity problem in estimated model, all climatic variables have been demeaned. To calculate the panel regression model, Least Square (LS) technique with no weights is utilized. Based on the study, These Features has been believed to check the strength of the model. Depending on the methodology, the wheat production model has calculated the econometric influence on climatic change normal the agricultural sector in the four districts that we selected in Southern Punjab for the period of 1983-2013. The Econometric approach is utilized for evaluation of climatic impact, i.e. Least Square (LS) with no weights with one-way fixed effect panel model specification with district fixed effects.

\section{Definition of Variables}

The selected districts of southern Punjab are unit of spatial analysis. And the farmer or farmland is the basic agent in land use. Data taken of thirty years from 19832013, so the Table 1 contains defined dependent and independent variables in study. Data collected from the different issues of the Punjab Developmental Statistics, National Fertilizer Developmental Centre, Islamabad and temperature and precipitation data from Pakistan Meteorological Department Lahore office. The categorization of independent variable is, Climatic and non-climatic variables. These variables are elaborated below:

\section{Table 1: Description of variables}




\begin{tabular}{|c|c|c|c|}
\hline Variable & Title & Definition & Source of data \\
\hline $\begin{array}{l}\text { Dependent } \\
\text { variable }\end{array}$ & $\mathrm{Y}=$ Wheat production & Wheat production at district level & $\begin{array}{l}\text { Punjab Development Statistics } \\
(1983-2013)\end{array}$ \\
\hline \multirow{4}{*}{$\begin{array}{l}\text { Independent } \\
\text { (Non } \\
\text { Climatic) }\end{array}$} & $\begin{array}{l}\text { Area under cultivation } \\
\text { (A) }\end{array}$ & $\begin{array}{l}\text { Per year use of land for } \\
\text { wheat production. At the } \\
\text { districts Level, the unit of } \\
\text { analysis is Thousand } \\
\text { Hectares. }\end{array}$ & $\begin{array}{l}\text { Punjab Developmental Statistics } \\
(1983-2013)\end{array}$ \\
\hline & $\begin{array}{l}\text { Total number of diesel } \\
\text { and electric tube wells } \\
\text { (private and ownership) } \\
\text { installed (TW) }\end{array}$ & $\begin{array}{l}\text { The total number of diesel and } \\
\text { electric tube wells (private and } \\
\text { ownership) installed at district } \\
\text { level. }\end{array}$ & $\begin{array}{l}\text { Punjab Development Statistics } \\
(1983-2013)\end{array}$ \\
\hline & $\begin{array}{l}\text { Total number of tractors } \\
\text { by ownership and private } \\
\text { purchase (Trt) }\end{array}$ & $\begin{array}{l}\text { The total number of tractors by } \\
\text { ownership and private purchase } \\
\text { installed at district level. }\end{array}$ & $\begin{array}{l}\text { Punjab Development Statistics } \\
(1983-2013)\end{array}$ \\
\hline & $\begin{array}{l}\text { Total consumption of } \\
\text { fertilizer in nutrients ton } \\
\text { (F) }\end{array}$ & $\begin{array}{l}\text { The total consumption of fertilizer } \\
\text { in nutrients ton at district level. }\end{array}$ & $\begin{array}{l}\text { Report of National Fertilizer } \\
\text { Development Centre, Islamabad } \\
(1983-2013)\end{array}$ \\
\hline \multirow{2}{*}{$\begin{array}{l}\text { Independent } \\
\text { (Climatic } \\
\text { Variables) }\end{array}$} & Temperature & $\begin{array}{l}\text { Degree Celsius Temperature }=0 \mathrm{C} \\
\text { normal mean for November- April }\end{array}$ & $\begin{array}{l}\text { Pakistan Meteorological } \\
\text { Department (1983-2013) }\end{array}$ \\
\hline & Precipitation & $\begin{array}{l}\text { Precipitation (millimeters) } \\
\text { normal mean for } \\
\text { (Nov-April) }\end{array}$ & $\begin{array}{l}\text { Pakistan Meteorological } \\
\text { Department (1983-2013) }\end{array}$ \\
\hline
\end{tabular}

\section{Results and Discussion}

$\mathrm{R}^{2}$ value is $0.86\left(\mathrm{R}^{2}=0.86\right)$ it means that the explanatory variables (Climatic and non-climatic) explained $86 \%$ variation in the dependent variable. Fstats exhibits that, the joint significance of explanatory variables with dependent variable, average wheat production is highly significant. From all the calculated various characteristics of the model, the most fitting model is announced. To represent inertia in wheat production a Lag dependent variable is also utilized. As proved by the DW statistics the deficiency of serial correlation problems and the F-statistics presents general significance of the model.

Four districts of Punjab and 30 points of time has been taken into consideration for the study. The panel fixed effect model was utilized for cross section for acquiring data on heterogeneity in districts. The technique we utilized to operate the panel regression is agricultural production model with No Weights technique. For the purpose of assessment, quadratic forms of climatic variables with linear forms were also evaluated. There's consistency of using quadratic form in literature. To acquire all different options of nonlinearities in climatic sensitivities, quadratic forms were utilized (Lee et al., 2012). The minimal value of climatic variable at the production mean is shown by the linear term of climatic variables, and the nature of relationship between climatic variables and production value is shown by the quadratic terms as given below: 
Table 2: Panel Estimation Results

\begin{tabular}{lc}
\hline Variables & Coefficients \\
\hline & Climatic variables \\
\hline December Temperature & -0.30 \\
December Temperature Squared & 0.0086 \\
March Temperature & $-0.34^{*}$ \\
March Temperature Squared & $0.0083^{*}$ \\
April Temperature & $0.12^{*}$ \\
April Temperature Squared & $-0.0016^{*}$ \\
December precipitation & $0.010^{*}$ \\
December precipitation Squared & $-0.00018^{*}$ \\
March precipitation & $0.0079 \mathrm{~ns}$ \\
March precipitation Squared & $-0.00018^{* * *}$ \\
April precipitation & $-0.0047 \mathrm{~ns}$ \\
April precipitation Squared & $0.000058 \mathrm{~ns}$ \\
\hline
\end{tabular}

Non-Climatic

\begin{tabular}{lc}
\hline $\log$ (Area under Cultivation) & $0.45^{*}$ \\
$\log$ (Total number of diesel and electric tube wells) & $0.21^{*}$ \\
Log (Total number of tractors) & $0.26^{*}$ \\
Log (Total consumption of fertilizer in nutrients ton) & $0.14^{*}$ \\
\hline
\end{tabular}

District Fixed Effects

\begin{tabular}{cc}
\hline Multan & -0.089 \\
Bahawalnagar & 0.062 \\
Rahim Yar Khan & -0.026 \\
Bahawalpur & 0.042 \\
$\mathrm{R}^{2}$ & 0.86 \\
Adjusted $\mathrm{R}^{2}$ & 0.82 \\
F-statistics & 37.81 \\
Durban-Watson statistics & 2.01 \\
\hline
\end{tabular}

Note: $*$, **, and $* * *$ denotes significance at $1 \%, 5 \%, 10 \%$, respectively Source: Author's own Calculation

Climatic Variables: Estimated conclusions of the study are discussed in this section.In recent decades anthropogenic activities have becoming the dominating factor towards the climatic problems such as irregular rainfall pattern and rise in temperature (Khattak and Shabbir, 2012). Investigated results showed that the 
mean December temperature has a non-significant impact in the overtime production of wheat crop with the coefficient value of -0.03 with the negative sign and this could be due to mean temperature rise that caused low seed germination, extended growing period and stress in temperature at the grain filling stage, the conclusions that we got in the model are like the previous results (Ayinde et al., 2010). The square term of the December temperature shows the nature of relationship is unexpected sign with the wheat production, these conclusions also resemble to the concluded result of the previous research (Siddiqui et al., 2012). The estimated result for the mean temperature March showed highly significant impact in the overtime production of wheat crop with the coefficient -0.34 which means it has significant relationship and square term is also shows significant relationship at 1 percent level of significance. Wheat is less sensitive to temperature on vegetative state (Entz and Fowler, 1988). But when the temperature above the $25^{\circ} \mathrm{C}$ it negatively impact on vegetative growth (Porter and Gawith, 1999). The maximum temperature level also calculated in the descriptive analysis so, in this study it shows significant relationship with wheat production. Maximum temperature has great significance due to the determination of vegetation period length (Cabas et al., 2010; Tunde et al., 2011). The square term of the mean temperature of March showed the significant relationship at 1 percent level of significance with the wheat production consistent with previous findings (Ahmed at al., 2011).

From the calculated results for the mean temperature of the April month, these results showed that significant impact on the wheat production with the value of 0.12 . Because of the rise in temperature at the harvesting stage cause the positive impact on production; furthermore these result also in line with the results of Dasgupta et al. (2013) when they estimated the effect of climatic change on food grain productivity in Indian states. Square form result of the result showed significant relationship at 1 percent level of significance with value -0.00017 these results were like the conclusive results of Weber and Hauer (2003) and Mendelsohn and Reinsborough (2007) both calculated that with the rise in temperature and precipitation Canadian farmland value also raised. Precipitation has a very important variable in the wheat production. According to the literature, precipitation had shown in mixed cropping zone of Punjab. With the sufficient rainfall wheat production increased by 275.77 $\mathrm{kg}$ ha-1(Ashfaq et al., 2011). The wheat production was anticipated to have an inverse effect from Variable precipitation. Elevation in proportionate variability of rain is represented by elevation in the rainfall co-variance and it's expected to decline the crop yields level and elevation in yield variation (Cabas et al., 2010; Seo and Mendelsohn, 2008). The precipitation regression results showed that the mean precipitation for the month of the December shows the non-significant impact on the wheat production with the value 0.010 at significance level of 1 percent. This could be the rise of precipitation significance impact on the wheat production. These results were similar to the Aggarwal (2008). The square term value showed the significant relationship with the value is -0.00018 . The mean precipitation of the March showed the significant impact on the wheat production with the value of 0.0079 . It means the impact of mean precipitation on the wheat production was significantly on wheat production. This result was similar to the results observed by the Gifford et al. (1998) and Lobell et al. (2005). The square term of the mean precipitation of the March showed the significant relationship with wheat production. It means the precipitation on the vegetative growth significant effect on the production (Mishra et al., 2013; Holst et al., 2010).

The estimated results showed that the relationship between the mean precipitation of the April month and the wheat production gives the non-significant relationship with the value -0.004 , this shows that if precipitation increases in the harvesting stage then it increases the harvesting losses. This result was similar with result (Owusu-Sekyere et al., 2011) when he was estimating the climate change impact on crop production of Manifested area of Ghana also with the results (Ayinde et al., 2010). Furthermore this estimation also matched with results (Zilberman et al., 2005).The square term of the April mean precipitation showed the nonsignificant relationship between the precipitation and the wheat production. It means, if the precipitation increases at this stage then production decreases vice versa. This result was in line with the previous results (Rowhani et al., 2011; Zhu et al., 2013).

Non-Climatic: As the analysis has shown, there is considerable positive effect of used fertilizer on wheat crop production. Therefore, one of the way to overcome the declined production was to upgrade the approach of districts and most importantly of the farmer to fertilizer. This will become one of the primal modification step, but this will need an active support and implementation by respective government agencies. One of the primal feature will be the fertilizer availability and applying it effectively, e.g. by using strong extension services. Moreover, the farmer will need a handsome share of credits given to the agricultural sector to apply this adoptive measure (Akram et al., 2008; Iqbal et al., 2003). As shown by the results that a positive relationship in the wheat production and the log of the fertilizers was seen it means $1 \%$ increase in the fertilizers cause the effect on wheat production with $14 \%$ increase in wheat production. The conclusive result in the model is also like the conclusive result of the Ludwig and Asseng (2006). As a precaution to deal with the fact, that $90 \%$ of the major crop wheat is irrigated, the model included a proxy for irrigation. Still, the model exhibited high significant effect of variable public tube wells per district on food crop production. This was most likely because of the result of that the public tube wells are related with the tragedy of waterlogging. But these public tube wells are uneconomical to operate and repair, so to improve the agricultural production and to decrease the government expenditures, these tub wells must be replaced with 
farmer owned small tube wells. The model illustrates that these privately owned and operated tube wells on form output will have profound positive effect. To this effect, until the public tube wells are substituted with equal or greater alternate pumping capacity in private sector to deal with waterlogging, the public tube wells should be kept operational (Ahmed and Schmitz, 2011). The results revealed that there was positive relationship between the wheat production and the total number of tube wells. This shows $1 \%$ installation of more tube wells would increase $21 \%$ increase of wheat production. The total numbers of tractors owned by both public and private have significant impact on wheat production. The results showed that the 1 percent increase in the number of tractors cause the $26 \%$ increase in the wheat production. There is consistency in these conclusions and the results of Sher and Ahmad (2013).

Districts Fixed Effects: The unseen time invariable determining factors of productivity can be assimilated by the district fixed effects. Lesser wheat production is shown by negative district coefficients in comparison to the positive district coefficients. Under the fixed effects the heterogeneity in coefficients of the production values is caused by unnoticed factors. In the model, the missing or unnoticed factors are not added, like fertility of land and irrigation etc. In the Model, the constant intercept exhibits the mean productivity of the selected four districts because of district specified features and the district's artificial copies (dummy) coefficients exhibits fluctuation from this average productivity. The importance of coefficients of these dummy variables shows that district specified attributes do have importance in wheat productivity. These Conclusions showed that Multan, Bahawalnagar, Rahim Yar Khan and Bahawalpur coefficients respectively are -0.0089 , $0.062,-0.026$ and 0.042 .The negative value of Multan coefficient showed the non-significant relationship with the production. Multan is largest and urban city of southern Punjab and the heart of the Cotton- Wheat cropping pattern. Multan had large share in production of wheat in 1980s but due to floods its production decline in the recent years. One of the intriguing conclusion was the Negative F.E coefficients for District Rahim Yar Khan. The reason that can be traced is most of the farmers preferring the sugarcane as compared to the wheat. Because there are four sugar mills functioned in the district and three are near to completion.

Marginal Climate Impacts: Constant slopes represent the linear coefficient and non-linear slopes represent the squared coefficients that are the functions of climatic variables. It wasn't possible for linear coefficients and squared coefficients to interpret the amount of influence of climatic variables individually. To represent the intensity of the influence of climatic variables on wheat productivity, MCI (Marginal Climatic Impact) for each climatic variable set (Linear coefficients or squared coefficients) has been jointly estimated. Taking in mind the discussion 4.4 , if the productivity of wheat are represented in quadratic functions of climatic variables, the partial derivatives of dependent variable wheat productivity with respect to climatic variables should be.

Table 3: Marginal Impacts of Climate on Wheat Production

\begin{tabular}{lccc}
\hline Months & December & March & April \\
\hline Temperature & -26.94 & 22.82 & 17.08 \\
Precipitation & 5.17 & 2.19 & -2.21 \\
\hline
\end{tabular}

Source: Author's own Calculation

On an average, most crops have harmful impact form rising mean temperature, ranging from significantly damaging impact up to 6 percent for corn to a lesser impact on wheat, soybean and sorghum. Evidently, the extent of damaging from one degree increase in mean temperature is not harmful as predicted by Lobell and Asner (2003). Little rise in temperature and precipitation in months of December and March rises the agricultural productivity in these districts. Still, little rise in precipitation in April month decreases wheat productivity. Monthly temperature and precipitation elasticities are estimated utilizing the coefficients of regression and mean values of climatic variables from the model shown in the Table 4.8. When the temperature and precipitation in the month of December increase $1 \%$ then the production increases $0.0016 \%$ and decreases $2.61 \%$ respectively. However, increase in temperature after the sowing increases the production and also the precipitation effect on the germination of the seed. If temperature and the precipitation increase $1 \%$ in the month of March then the production increases $0.85 \%$ and $0.04 \%$ respectively. When mean temperature and precipitation of the month April increases 1\% its impact on wheat production increases $0.83 \%$ and decreases 0.02 respectively. At the time of harvesting increase in precipitation increases the harvesting losses (Porter and Gawith, 1999). 
Table 4: Elasticities of climate variables on wheat Production

\begin{tabular}{lccc}
\hline Months & December & March & April \\
\hline Temperature & -0.67 & 0.85 & 0.83 \\
Precipitation & 0.04 & 0.04 & -0.03 \\
\hline
\end{tabular}

Source: Author's own Calculation

This study was done to calculate the climatic change impact on wheat productivity in southern Punjab by utilizing panel data. Changing climatic condition and their effect on grain crops were estimated. Therefore, the Government of Pakistan devises the policies to encourage farmers for increasing the wheat production through allocating more and more area to wheat crop, using appropriate management practices, recommended farm inputs, adoption of new technologies, new varieties which are heat resistant especially suited the climatic conditions of Southern Punjab. The Panel data used to determine the climate change impact on wheat production. The data from 1983-2013 were gathered on wheat area, production, fertilizer, tractors, number of tube wells and climatic variables. In selected districts from 1983 and 2013, the method of Least Square regression was used by F.E Region-level panel analysis.

The main target of this study was to measure the effect of climatic change normal to have a viable and maintainable agricultural sector development at the regional level. Meaning, if the climatic change decrease or increase the value of wheat. With this thinking, this study was the first attempt to measure the effect of climatic change on the sector of Agriculture of the southern Punjab. The present study was different from the previous studies because this study has estimated the effects of climatic change on wheat productivity separately in the selected districts of southern Punjab and also using fertilizer consumption of each district. As an initiative of model specification the chances of any structural variation in the regression of four selected districts, Multan, Bahawalnagar, Rahim Yar Khan and Bahawalpur was checked. The aim of this study was to estimate the effect of climatic change on wheat productivity in Punjab southern zone, because the contribution of only Punjab is near to 76 percent in the total wheat productivity and area, so Punjab was chosen for analysis. For ongoing analysis cotton-wheat agroecological zone, was chosen to represent all wheat producing areas of Southern Punjab. This zone contribution is $30 \%$ to total production of wheat in the country. Multan, Bahawalnagar, Rahim Yar Khan and Bahawalpur districts were chosen from this zone because they account for largest share in the total area of the Punjab in terms of wheat area. Multan covers 4.73 percent while Bahawalpur covers 4.33 percent of the total wheat area; both are larger than all districts from Punjab.
Using descriptive analyses, it was found that wheat production has increased overtime mainly due to the increase in land area allocated to the wheat production. Population also showed an increasing trend over the study period. However, increase in the population was higher compared to an increase in wheat production. Econometric analysis was done separately for the districts effect on the wheat production to determine the effect of climatic change on wheat productivity. Results of the regression analysis showed that the rise in temperature was seen to impact the wheat production but in long run the temperature rise impacted positively on production of wheat. Likewise, the rise in precipitation affected negatively in both long and short term. In the beginning temperature increase was good for wheat productivity. But, in vegetative growth period very high temperature effect on production, more rise in temperature turns to be detrimental for wheat productivity. Interestingly, the rise in precipitation harms the wheat production at the maturity stage. The minimal climatic influence is calculated to represent the intensity and also examine the jointed importance of linear and squared coefficients on climatic variables. As the Results had represented that in month of November, an increase in temperature had the positive value on the wheat production but it is in elastic and like the same in the case of the month January. While the relationship goes in the month of April then elasticity shows the elastic relationship between the climatic variables and the wheat production.

\section{Conclusion}

The study concentrates on fluctuations in climatic indicators on productivity of wheat crop in Southern Punjab, Pakistan. Results showed that different level of temperature and precipitation affected the crop production. The impact of temperature and precipitation are both positive and negative on crop productivity. Temperature at initial stage of wheat crop grown in December negatively affected the crop productivity, while high temperature has positive impact at later stages of wheat crop. Similarly high precipitation on sowing stage has positive effect on seed germination. Precipitation at vegetative growth stage has positive impact on wheat production. Increase in Precipitation at harvesting level increases the harvesting losses. The study also focused on the efficient use of fertilizers, tube wells and tractors on the wheat production. The positive impact of fertilizer use, tractors and tube wells shows that 
with the efficient use of these inputs production can be enhanced to meet the desire needs of the increasing population and food security as well.

Essential reasons for the loss in production is the abnormal behavior of the climate. Temperature shows very significant impact on the sowing time. If temperature will be high or low from the range then it effect the seed germination. So hence proper time should be adopted for wheat sowing. Similarly early sowing will be helpful because of the high temperature in the study area. Precipitation is out of control, but helpful for plant because it provides moisture in the air. As well as rainy water absorb nitrogen from the air and make it available for the plant. As in the absence of the precipitation timely irrigation and application of fertilizer will cover the losses cause by the absence of precipitation. Food security can be overcome by the efficient use of fertilizers, more use of machinery and also by increasing the cultivated area under the crop. These results revealed that the efficient use of the domestic resources can be helpful to increase the wheat production.

\section{References}

Aggarwal, P.K. 2008. Global Climate Change and Indian Agriculture: Impacts, Adaptation and Mitigation. Indian Journal of Agriculture Science, 78, 911919.

Ahmed, M.N., Schmitz, M., 2011. Economic Assessment of the Impact of Climate Change on the Agriculture of Pakistan. Business and Economic Horizons, 4, 1-12.

Ahmed, M., Fayyaz-ul-Hassan, M., Aslam, M., Akram, M.N., Akmal, M., 2011. Regression model for the study of sole and cumulative effect of temperature and solar radiation on wheat yield. African Journal of Biotechnol, 45, 9114-9121.

Akram, W., Hussain, Z., Sabir H. M., Hussain, I., 2008. Impact of Agricultural Credit on Growth and Poverty in Pakistan (time series analysis through error correction model). European Journal of Scientific Research, 23, 243-251.

Ashfaq, M., Zulfiqar, F., Sarwar, I., Quddus, M.A., Baig, I.A., 2011. Impact of Climate Change on Wheat Productivity in Mixed Cropping System of Punjab. Soil Environment, 30, 110-114.

Ayinde, O.E., Ajewole, O.O., Ogunlade, I., Adewumi, M.O., 2010. Empirical Analysis of Agricultural Production and Climate Change: A Case Study of Nigeria. Journal of Sustainable Development in Africa, 12, 253-345.

Bashir, A., Mahmood, M.A., Shiekh, A.D., Kashif, M., 2006. Causes of Wheat Yield Decline in the Irrigated Punjab. Pakistan Journal of Agriculture Science, 44, 20-27.

Cabas, J., Weersink, A., Olale, E., 2010. Crop Yield Response to Economic, Site and Climatic variables. Climatic Change, 101, 599-616.
Dasgupta, P., Bhattacharjee, D., Kumari,A., 2013. Socioeconomic Analysis of Climate Change Impacts on Food Grain Production in Indian States. Journal of Environmental Development, 8, 5-21.

Department for Environment, Food and Rural Affairs (DEFRA), 2005. India-UK Collaboration on Impacts of Climate change in India.

Entz, M. H., Fowler, D.B., 1988. Critical stress periods affecting productivity of no-till winter wheat in western Canada. Agron. J., 80, 987-992.

Gifford, R., Angus, J., Barrett, D., Passioura, J., Rawson, H., Richards, R., 1998. Climate change and Australian wheat yield. Nature, 391, 448-449.

GOP (Government of Pakistan), 2014. Pakistan Meteorological Department, Regional Meteorological Department Lahore.

GOP (Government of Pakistan), 2015. Economic survey of Pakistan 2014-15, Government of Pakistan. Finance Division Economic Advisor's Wing, Islamabad.

Greene, W.H., 2003. Econometric analysis. Pearson Education India, 368-370.

Holst, R., Yu, X., Grun, C., 2010. Climate change, risk and grain production in China. In 2010 Annual Meeting, July 25-27, 2010, Denver, Colorado (No. 61177). Agricultural and Applied Economics Association.

Iqbal, M., Ahmad, M., Abbas, K., 2003. The impact of institutional credit on agricultural production in Pakistan. The Pakistan Development Review, 42, 469-485.

Javed, I., Ashfaq, M., Adil, S.A., Bakhsh, K., 2016. Analysis of agricultural trade between Pakistan and United Arab Emirates: An application of gravity model, j agric. res., 54, 787-799.

Khattak, P., Shabbir,R., 2012. Temporal Analysis of Wheat yield and Climatic Trends in Pakistan. Elixir Agriculture, 52, 11598-11603.

Kisana, N.S., 2004. National Coordinated Wheat Program. National Agriculture Research Centre, Islamabad.

Kurukulasuriya, P., Mendelsohn, R., 2008. A Ricardian Analysis of the Impact of Climate Change on African Cropland. African Journal of Agricultural and Resource Economics, 2, 1-23.

Lee, J., Nadolnyak, D.A., Hartarska, V.M., 2012. Impact of Climate Change on Agricultural Production in Asian Countries: Evidence from Panel Study. Annual Meeting, February 4-7. Southern Agricultural Economics Association.

Lobell, B.D., Ortiz-Monsanterio, J.I., Anser, G.P., Matson, P.A., Naylor, L.R., Falcon, W.P., 2005. Analysis of wheat yield and climatic trends in Mexico. Field Crops Research, 94, 250-256. 
Lobell, D.B., Asner, G.P., 2003. Climate and management contributions to recent trends in U.S. agricultural yields. Science, 299(299), 1032.

Ludwig, F., Asseng, S., 2006. Climate change impacts on wheat production in a Mediterranean environment in Western Australia. Agric Sys, 90, 159-179.

Mendelsohn, R., Dinar, A., 2009. Land Use and Climate Change Interactions. Annual Review of Resource Economics, 1, 309-332.

Mendelsohn, R., Reinsborough, M., 2007. A Ricardian analysis of US and Canadian Farmland. Climate Change, 81, 9-17.

Mendelsohn, R., Nordhaus, W.D., Shaw, D., 1994. The impact of Global Warming on Agriculture: A Ricardian Analysis. The American Economic Review, 84, 753-771.

Mishra, A., Singh, R., Raghuwanshi, N.S., Chatterjee, C., Froebrich, J., 2013. Spatial variability of Climate Change Impacts on Yield of Rice and Wheat in the Indian Ganga Basin. Science of the Total Environment, 468-469: S132-S138.

Mundlak, Y., 1988. Endogenous Technology and the Measurement of Productivity. In Agricultural Productivity: Measurement and Explanation, S. M. Capablo and J. M. Antle, edition. Resources for the Future. 316-31. Washington D.C.

Mundlak, Y., Larson, D.F., Butzer, R., 1999. Rethinking Within and Between Regressions: The Case of Agricultural Production Function. Annales' Economieet de Statistique, 46, 55-56.

Owusu-Sekyere, J.D., Alhassan, M., Nyarko, B.K., 2011. Assessment of climate shift and crop yields in the Cape Coast area in the Central Region of Ghana. ARPN Journal of Agricultural and Biological Science, 6: 1-6.

Porter R. J., Gawith, M., 1999. Temperatures and the Growth and Development of Wheat: A Review. European Journal of Agronomy, 10, 23-36.

Rajin, A.M., Leary, G.O., McNeil, D., Hossain, H., Nelson, R., 2007. Climate change Impact on Rainfed Wheat in South-Eastern Australia. Field Crops Resources, 104, 139-147.

Rejesus, R.M., Heisey, P.W., Smale, M., 1999. Source of Productivity Growth in Wheat. A Review of Recent Performance and Medium to Long-term Prospects. CIMMYT Economics Paper 99-05. Mexico D. F.

Rosegrant, M.W., Ewing, M., Yohe, G., Burton, I., Huq, S., Valmonte-Santos, R., 2008. Climate Change and Agriculture Threats and Opportunities. Federal Ministry for Economic Cooperation and
Development, 1-36.

Rowhani, P., Lobell, D.B., Linderman, M., Ramankutty, N., 2011. Climate variability and crop production in Tanzania. Agricultural and Forest Meteorology, 151, 449-460.

Seo, S.N., Mendelsohn, R., 2008. A Ricardian analysis of the impact of climate change on South American farms. Chilean Journal of Agricultural Research, 68, 69-79.

Shabbir, G., Ahmad, N.H., Akram, Z., Tabassum, M.I., 2011. Genetic behavior and analysis of some yield traits in wheat (Triticum Aestivum L.) genotype. J. Agric. Res., 49(1), 1-9.

Sher, F., Ahmad, E., 2013. Forecasting Wheat Production of Pakistan. International Journal of Agriculture and Biology, 2, 373-378.

Siddiqui, R., Samad, G., Nasir, M., Jalil, H.H., 2012. The Impact of Climate Change on Major Agricultural Crops: Evidence from Punjab, Pakistan. The Pakistan Development Review, 51(4), 261-276.

Stock, J.H., Watson, M.W., 2003. Introduction to Econometrics. Singapore: Pearson Education.

Task Force on Climate Change (TFCC), 2010. Final Report, Islamabad: Planning Commission of Pakistan.

Tunde, M., Usman, B.A., Olawepo, V.O., 2011. Effects of climatic variables on crop production in Patigi L. G. A., Kwara State, Nigeria. Journal of Geogre Regional Plan, 4, 695-700.

Weber, M., Hauer, G., 2003. A Regional Analysis of Climate Change Impacts on Canadian Agriculture. Canadian Public Policy, 24, 163-180.

Wei, X., Yinlong, X., Erda, L., 2005. The Simulation of yield Variability of Winter Wheat and its corresponding Adaptation options under Climate Change. Chinese Agriculture Sciences, 45, 123154.

Yang, X., Chen, C.H., Luo, Q., Li, L., Yu, Q., 2011. Climate Change Effects on Wheat yield and Water use in Oasis Cropland. International Journal of Plant Production, 5, 83-94.

Zhu, T., Ringler, C., Iqbal, M.M., Sulser, T.B., Goheer, M.A., 2013. Climate change impacts and adaptation options for water and food in Pakistan: scenario analysis using an integrated global water and food projections model. Water International, 38(5), 651-669.

Zilberman, D., Liu, X., Roland-Holst, D., Sunding, D., 2005. The economics of climate change in agriculture. Mitigation and Adaptation Strategies for Global Change, 9, 365-382. 